\title{
Analysis on the Construction and Regulation of the Financial Legal System under the Perspective of the Economic Law
}

\author{
Ni Xue \\ Hainan Vocational College of Political Science and Law, Haikou, 571100, China \\ nixue123@163.com
}

Keywords: Economic law; Financial law; Building

\begin{abstract}
The Finance plays an important role in the process of development of modern economy; the financial security seriously affects the stability of the economy. It is closely combined with the environment, the economy, and the human society life; The financial stability is the core of the national economy, the enterprise operation and human life are related to it, in the process of construction of market economy, the development of financial markets is one of essential work to ensure stable social economic order, and the financial markets must be developed and stabilized. This article will focus on the building and regulation of the financial legal system.
\end{abstract}

\section{Introduction}

The law is the standard main body behaviour, the rules of adjusting social relations. To confirm and maintain financial ecological balance, financial law has a set of values, norms and implementation plan, such as financial transaction rules, property rules, etc., as the basic rules for achieving and maintaining financial ecological balance, both specific provisions in the financial legal system. Should say, improve and perfect the financial legal system is a security and stability of the financial market is the first condition of existence. Using the rule of law thinking and way to push on the modernization of the country under the rule of law, is the basic requirement of comprehensively deepen reform, is to achieve the great rejuvenation of the Chinese nation plays an important role in promoting the Chinese dream. With the improvement of the system of socialist market economy and the deepening of financial reform, gradually established a relatively perfect financial legal system in our country, the financial industry development into the orbit of legalization and standardization. But the construction of rule of law there is many weak links, impotence and could not be in accordance with and excessive regulation and insufficient regulation phenomenon exists to a certain extent. Current our country economy has entered a new normal, financial reform also gradually to the deep zone, sets up the rule of law thinking, and promote the modernization of financial governance is the key to comprehensively deepen the financial reform.

\section{The importance of the construction of the financial legal system}

The construction of financial legal system, the core to adhere to the law is supreme

The rule of law thinking throughout the whole process of the financial operation and management, financial relationship with a legal and truly administration accords to law, in accordance with law, regulation and management in accordance with the law. As the general secretary pointed out, "which step to the transition of government function, the rule of law construction will follow up to which step". Financial sector development to which step, is a step to follow up to which financial rule of law. To finance new thing, should plan ahead, relevant laws and regulations, to adapt to the current situation of financial legal system should be revised or clean up. At the same time, should act in strict accordance with the financial laws. Anyone or any department should not beyond the legal intervention in the financial affairs and activities, the real financial management system of public power in the cage. To legal norms and adjust financial regulators, financial institutions and financial markets, finance, customer, the relationship between the security with the rule of law and standardize financial innovation, handling of the financial risks in law thinking, to protect the rights and interests 
of investors, creditors, depositors and the insurer, maintain a good financial order and financial stability.

The construction of financial legal system, we should correctly handle the relationship between the administrative, legal and market

Within the bounds of the law to the market enough space and flexibility, we must realize that the law can sometimes be relatively lagging behind financial innovation and practice, especially in our country is in the period of social transition, the socialist market economic system and mechanism is not perfect, many reforms under exploration, not hidebound. Both in legislation and law enforcement should be moderate risk tolerance and the innovation, space and leeway to financial reform. Especially to deal with the relationship between the government and the market at present stage, to deal with the relationship between the visible hand and invisible hand, pay attention to market regulation and legal regulation, should not only prevent insufficient regulation, also want to prevent excessive regulation, introducing the list of positive and negative inventory management system, truly for market main body no ban can be "' method, for the government to no authorization for" law ".

\section{The problem of the financial legal system in our country}

From the perspective of financial operation, complete financial legal system concrete specification shall include the following: one is the specification of the financial organization, financial institutions such as the legal status, nature, organization, organizational forms, governance mechanism, market exit, etc; The second is financial regulation specifications, such as regulators set, regulatory functions, financial supervision system, market access regulation, financial prudent exit regulation, market supervision, etc; Third, financial operations standard, such as financial institutions to carry out financial business activities should comply with the rules; Four is a financial transaction specification, such as the rights of confirmation and protection, trading results and protection rules, etc. Although our country has established "the people's bank of China" as the core of financial legal system, the comprehensive building of financial institutions in the organic law, finance, business management, financial macro-control and financial supervision law legal system, but the international and domestic financial practice with each passing day, our country finance on \&on the enrichment and perfection of legal system. It is embodied in the following respects.

The financial legal system has been initially formed, but there is also a blank and fuzzy area

One is the deposit insurance system has not been established. At the end of 1997, the people's bank of China will set up deposit insurance research team, after years of research; he failed to establish deposit insurance system. With the acceleration development of China's financial opening and financial regulation gradually relaxed, introduced a to ensure financial security to protect against financial crisis of the deposit insurance system is more and more necessary. Second, the financial institutions market exit system has yet to launch. We will accelerate the establishment of a financial institutions market withdrawal mechanism, which is beneficial to clear in time not healthy body in the financial system, to ensure the health of the financial system. Third, private equity funds, industry does not get the corresponding legal status. Private equity fund in our country and industry in the financial markets have a large number of existences, but so far there are no corresponding laws, regulations and administrative rules on the specification, long-term extrajudicial run against the development of private equity fund industry and fund. In short, China's financial markets are in urgent need of the futures law by the financial institutions bankruptcy law deposit insurance law system and other regulatory laws.

From the point of view of financial innovation, the financial innovation in our country is woefully inadequate laws and regulations

As a result of the current our country finance system is a separate operation, without a unified financial innovation of the laws and regulations. On December 5, 2006, the China banking regulatory commission formally announced "the commercial bank financial innovation to guide", this is China's first legal norms about financial innovation, but the securities industry and insurance industry has not formulated the corresponding laws and regulations. In particular, a conflict is related to the current legal system of financial innovation behavior, the commercial bank law "securities law" and 
"insurance law" the trust law in accordance with the principle of separation of banking regulation, and the development of financial innovation has the character of the mixed financial business. 2 it is contradictory between different regulatory rules or inconsistencies, such as the securities and futures commission for securities companies to issue corporate bonds must be guaranteed by the bank, and the China banking regulatory commission has strict limits on Banks to provide guarantee for securities companies to issue bonds.

\section{The guiding ideology and principle to reconstruct the financial law system}

In the process of establishing and perfecting the financial law system, we should always follow these eight guidelines: specification, stable, fast, and strictly. This specification, embodied in the day-to-day conduct of financial institutions must be strictly carried out in accordance with the relevant requirements, at the same time, you have to improve the system of the new law, to regulate the financial sector of activity and behavior; Stable, embodied in the financial unit of daily operations activities shall maintain and stabilize financial markets and safety as a benchmark, gradually develop their own business market; Rapid, specific refers to financial units should be the broad masses of customers to create efficient and effective financial products and the environment, and the government and regulators should be financial institutions to provide more effective guidance; Strict, specifically refers to the relevant departments should attach importance to and strictly regulated the activity and behavior of financial institutions, should adhere to the legal procedures, doing things according to law, and the customer should be strictly in accordance with the rules of financial, makes every effort to achieve financial institutions, governments and regulators, and ask the new target of win-win development of the client.

\section{To stick the decentralized management}

Adhere to the decentralized management, capital market and banking system q can form an effective firewall, it can effectively prevent and control the crisis occurrence, development, to have a crisis in take effective remedial measures. In view of this, the banking, securities, insurance and trust these four industries, must insist on decentralized management as the center, set up relevant firewall, so that more stable operation and development of industries.

\section{The recommendations of our country's financial security and financial law system}

Financial system in the national economic structure, belongs to the fragile and sensitive and extremely important link, in view of the western developed countries, the market economy is more developed and perfect financial system, including both formulate and implement monetary policy, take the macroeconomic regulation and control policy of the central bank, at the same time also has gathered many function and dominant role in the financial system of commercial Banks, there are a variety of non-bank financial units, they also have their respective duties.

\section{To guard against financial risks}

For the prevention and control financial risks in the financial sector is a long-term work, we should carefully analyze the macroeconomic situation, and to investigate the market, to discover the possible risks, ensure the security of the financial market, standardization development, at the same time also should perfect the relevant legal system to guard against financial risks.

\section{To pay attention to financial culture of compliance}

Pay attention to the compliance of the financial culture, build advanced financial markets of the various financial activities and behavior can be justified and strict legal procedure, to control and prevent financial risks and maintain social stability, the construction of financial culture is also a very important step of compliance. Don't operate according to related regulations, moral landslide, etc., these are the important factor affecting the stable harmonious financial markets, risk management, including compliance with two cases of violation they are the indispensable part in the process of management. Compliance namely, to establish relevant operation mechanism, perfect professional, independent of compliance management mechanism, and form a set of identification, evaluation and detection of compliance risk management system. The joint efforts of the implementation of the compliance, inseparable from the overall, supervision, etc., at the same time should also insist on compliance accountability. Compliance is also a kind of extension of financial supervision. Only with internal compliance regulation, can maintain the stability of the financial market order. 


\section{Conclusions}

While in our country the general pattern of financial legislation has been formed at present, but it is still in the blank of legislation stage in some important fields, such as the trust law, and the futures method, etc. Therefore to improve the financial legal system in our country, we should change the situation that could not be in accordance with, and to speed up the financial special legislative work, thus it makes our country important financial activities can implement laws. Some basic law of current financial rules are too principled, some financial innovation business was not included in the scope of legal supervision, some emerging of form a complete set of financial derivatives, the lack of corresponding legal regulation. Our country should be formulated by the financial law to form a complete set of rules and regulations.

\section{References}

[1] Grant Boyle. "A Review of Merging GHG Emissions Trading in North America: Fragmentation or Progress?". Alberta Law Review. 2012

[2] Jose Salazar. Environmental Finance: Linking Two Worlds. a workshop on Financial Innovations for Biodiversity Bratislava. 2012

[3] Sonia Labatt, Rodney R White. Environmental Finance. 2012

[4] JEUCKEN M. Sustainable Finance and Banking: The Financial Sector and the Future of the Planet. 2012

[5] Directive 2003/8/EC of the European Parliament and of the Council of 13 October 2003 establishing a scheme for green house gas emission allowance trading within the Community and amending Council Directive 96/61/EC.

[6] R. Doroau. The Emission Trading Scheme of the European Union. Legal Aspects of Implementing The Kyoto Protocol Mechanisms: Making Kyoto Work. 2012

[7] European Commission. Council Conclusions on the Further Development of the EU Position on a Comprehensive Post-2012 Climate Agreement. SEC(2009)101, SEC(2009)102. 